\title{
In $\boldsymbol{n}$ a I t.
}

\section{3u ben थlterthimern ber Şeilfunbe.}

Ehiron ber Phianribe. Der pelion 1831 . 4 . . . . 3

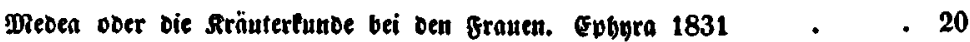

IBunbheillunft ber seroen bei somer 1832 . $\quad . \quad$. . . . 27

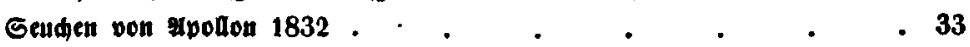

3nnere beiltunde. Podaliriod 1832 . . . . . . 46

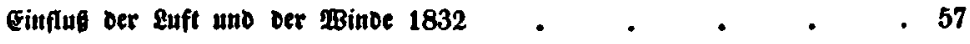

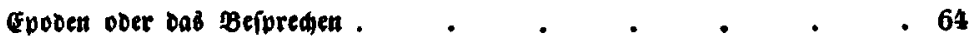

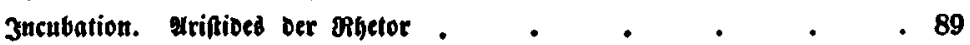

Snfanthropie ein querglaube uno eine stantbeit . $\quad . \quad$. 157

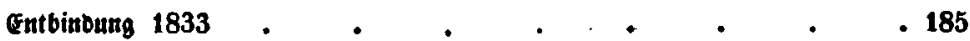

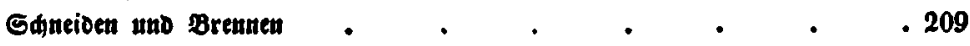

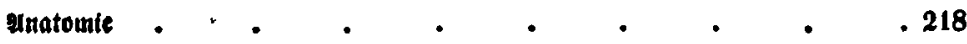

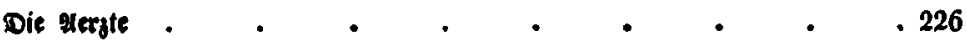

Griedifde $\mathfrak{s}$ nfdriften.

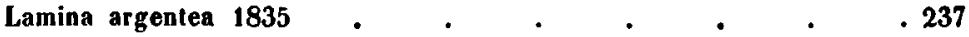

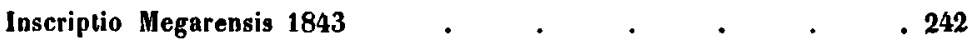

Inscriptio Spartana 1844 . $\quad . \quad . \quad . \quad . \quad . \quad . \quad . \quad .250$

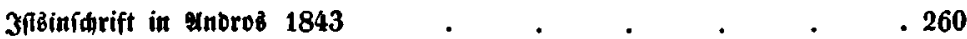

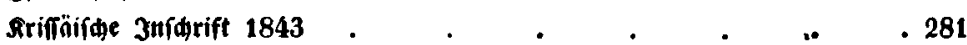

Brab und Squle Somers in 306 und Die Betrügereien deß Orafen Pafd

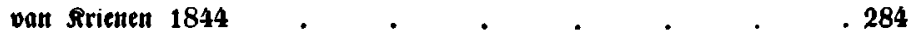

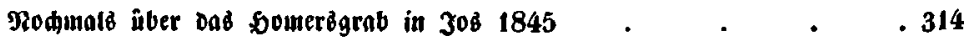

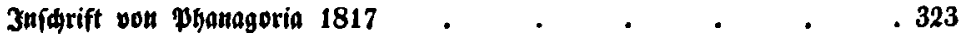




\section{3ur alten Runftgédidite.}

Geite

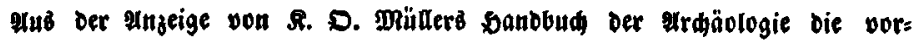

angebenden allgenteinen Bemertungen $1834 \quad . \quad . \quad . \quad .329$

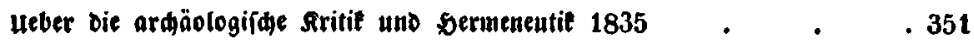

Sdaß̧äurer voer Orabuäler in Mìtenä uno Drdourenod? 1834 . 353

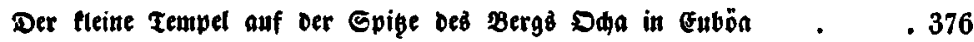

Fr. Jncobb über Den Reidthun oer Orieden an plaftifden Sunftwerten uno

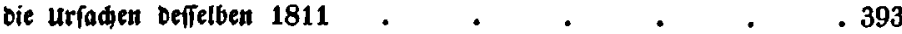

\&. Gaborn über bie Gtubien ber Eriedifden sünnter $1819 \quad .403$

Hever Die Gitte ber alten die Gculptur ju bemalen $1839 . \quad . \quad 407$

Die entauftifde Mlalerei $1836 \quad . \quad \ldots \quad . \quad . \quad . \quad . \quad .412$

Die Entauftil tin Oemälde 1833 . $\quad . \quad . \quad . \quad . \quad . \quad 427$

3roti Bemälde des Protogenes vei plinius 1837 . $. \quad . \quad .429$

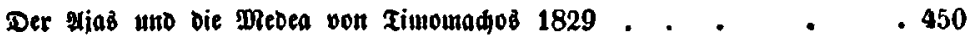

Die भleranderídladt bei 3ifod $1834 \quad . \quad . \quad . \quad . \quad .460$

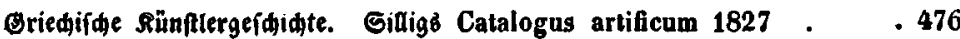

Die Therilleia mit Thierfiguren vergierte Bedher $1838 \quad . \quad . \quad .499$

Enojor $. \quad . \quad . \quad . \quad . \quad . \quad . \quad . \quad .516$

ueber Dą Beitalter dez Gitiadas 1833 . . . . . . 533

Dex feblex.

5. 17 3. 9. v. น. 1. ftügte.

- 86 פot. 43 3. 1 l. excan la sset.

- 151 3. 4 v. u. I. Diefe f. ne.

$-259-8$ v. u. I. ovane s c erent.

- 379-12 l. nenne f. nennt.

$-385-7$ v. и. เ. ३еоет.

$-386-3$ v. u. I. u w fdauliden.

Jum erfen band.

G. 46 3. 13 v. แ. I. Denn ft. ben.

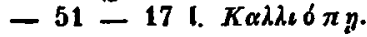

Ju zweiten.

5. XL 3. 13 I. le gteref. erf.

- XCVIII g. 3 เ. im อpre $e$ den. 